\title{
Percepções de estudantes de um curso de licenciatura em física sobre a leitura e a escrita no ensino e na aprendizagem de física
}

Joselaine Setlik joselainesw@gmail.com

orcid.org/0000-0003-3242-2550 (UFSC), Florianópolis, Santa Catarina, Brasil

\section{Ivanilda Higa}

ivanilda@ufpr.br

orcid.org/0000-0002-7277-3198

Universidade Federal do Paraná (UFPR), Curitiba, Paraná, Brasil

\section{RESUMO}

Este trabalho problematiza percepções de licenciandos em Física sobre a leitura e escrita de textos no ensino e na aprendizagem de física. Estudos têm indicado dificuldades que professores enfrentam ao utilizar esses processos, que podem estar ligadas com a não usualidade dessas práticas na própria formação inicial desses profissionais. São analisadas respostas de oito estudantes a um questionário organizado em três partes: a primeira visa conhecer o perfil do estudante, a segunda suas concepções sobre o uso e importância da leitura e da escrita na sua aprendizagem de conceitos físicos e formação profissional, e a terceira, suas percepções sobre essas práticas no Ensino Médio (colocando-se como futuro professor). As reflexões são construídas tendo em vista a teoria de Vigotski sobre leitura e escrita, assumindo-as como práticas socioculturais. Os resultados indicam que para estes futuros professores a leitura é considerada importante para a aprendizagem, principalmente pela compreensão conceitual que ela proporciona. A escrita de textos é vista como mais um recurso e, principalmente no Ensino Superior, associada à memorização de informações. O trabalho alerta para a necessidade de ampliar o olhar desses futuros professores sobre a leitura e a escrita através de discussões da temática durante sua formação inicial, além de incentivar o seu uso na aprendizagem de física, como alunos que são da Licenciatura.

PALAVRAS-CHAVE: Leitura. Escrita. Física. Formação de professores de física. Licenciatura. 


\section{INTRODUÇÃO}

A partir de Vigotski (2008) compreende-se a leitura como um processo dinâmico, ou seja, na interação do leitor com o texto é que as palavras assumem sentidos, podendo um texto escrito assumir vários sentidos dependendo de quem o interpreta e do contexto histórico-social. Segundo o mesmo autor, a escrita, por sua vez, exige planejamento e a criação de suportes expressivos e situacionais para a compreensão de um leitor. Nesse sentido, a escrita requer uma sistematização e organização do pensamento, que é constituído por palavras.

A leitura e a escrita podem ser compreendidas como processos importantes na construção do conhecimento, também relacionado à física, uma vez que requer uma ação ativa e consciente do indivíduo, refletindo sobre seu pensamento, tornando-o mais definido e concreto. Assim, a leitura e a escrita nas aulas de física podem ser mais do que instrumentos de transmissão de informações, ambas podem ser potenciais na construção de conhecimentos relacionados à ciência.

Pesquisas da área têm indicado que professores relatam dificuldades na utilização da leitura (para além das buscas de informações e muitas vezes de forma complementar) e da escrita (para além da cópia de conceitos físicos do quadro ou livro didático) em aulas de física (ASSIS; CARVALHO, 2008; ANDRADE; MARTINS, 2004).

Ao longo da história, algumas práticas e conteúdos se constituem como pertencentes a determinadas disciplinas escolares, existindo, portanto, uma cultura escolar (FORQUIN, 1993) que influencia as ações dos sujeitos pertencentes a esse espaço. Assim, apesar de possível e necessário, não é fácil propor formas de utilização da leitura e da escrita no ensino de física, pois, em geral, tanto no Ensino Médio quanto no Superior, essas não são consideradas práticas pertencentes à cultura da disciplina, na qual predominam a resolução de problemas e exercícios.

Durante o processo de formação inicial de professores de física também é importante que se façam discussões sobre a importância dos processos de leitura e escrita para ensinar e aprender física na escola. Essas discussões, quando realizadas, acontecem em geral nas disciplinas pedagógicas dos cursos de licenciatura. É necessário dar atenção e refletir sobre esse momento de formação dos licenciados para que ocorram mudanças na sala de aula na Educação Básica, e até mesmo no Ensino Superior, na forma de conceber e utilizar a leitura e a produção escrita.

Para além de discussões nas disciplinas de cunho pedagógico, será que a forma que o aluno vivencia o aprender com as práticas de leitura e de escrita pode influenciar no modo como ele, como futuro professor, vai desenvolver essas práticas com seus alunos? Se ele quase não usa a leitura, talvez isso possa limitálo em propor essa prática para ensinar.

Sob essa perspectiva, qual é o papel que estudantes de graduação atribuem a essas práticas em sua própria aprendizagem e para ensinar física? Existem relações entre o papel que ele atribui à leitura e escrita em sua própria aprendizagem como aluno e o papel que ele atribui à leitura e escrita para ensinar Física, como futuro professor? 
Qual tipo de leitura e de escrita estudantes de licenciatura consideram importante? Qual concepção subjacente de leitura e/ou escrita está presente na sua formação inicial?

Refletindo sobre a importância de um espaço de formação e da vivência do aluno do Ensino Superior, futuro professor, com as práticas de leitura e escrita, foi elaborado e aplicado um questionário a oito estudantes de um curso de Licenciatura em Física, no contexto de uma disciplina de Metodologia de Ensino, visando compreender as percepções desses sujeitos sobre a temática.

\section{A LEITURA E A ESCRITA DE TEXTOS NO ENSINO DE FÍSICA}

Diversos estudos têm discutido a importância da leitura e escrita de textos de diferentes gêneros no ensino e aprendizagem de física na Educação Básica. Na sequência serão apresentados resultados obtidos por diferentes pesquisadores da área em estudos desenvolvidos na Educação Básica e estudos na Formação inicial e na prática de Professores em Ciências da Natureza.

\section{LEITURA E ESCRITA NA EDUCAÇÃO BÁSICA}

Em relação à Leitura de textos de diversos gêneros no ensino de física, Silva (1997) analisou em sua dissertação os modos de leitura presentes em aulas dessa disciplina, através da observação de aulas e de entrevistas com os professores. Seu estudo mostra que muitas vezes a leitura estava limitada à utilização de textos associados a enunciados de exercícios quantitativos propostos no livro didático, fato que, mesmo alguns anos depois e em outras escolas, ainda descreve a realidade de muitas aulas dessa disciplina. O pesquisador, naquela ocasião, realizou intervenções nos contextos de leitura das aulas observadas, mostrando algumas possibilidades que os diferentes modos de leitura trazem para o ensino. $\mathrm{O}$ autor ressalta que a inserção de diferentes textos em sala de aula, de forma a envolver o aluno e tornar possível uma real aprendizagem por meio dela, não é algo simples e exige reflexão por parte dos educadores.

Outros trabalhos (ALMEIDA; RICON, 1993; ALMEIDA; SILVA; BABICHAK, 1999; ALMEIDA; SILVA; MACHADO, 2001) também analisaram e propuseram atividades de leitura em sala de aula defendendo principalmente sua importância para o desenvolvimento de conceitos físicos e o estabelecimento do diálogo da física com outras áreas do conhecimento, ou seja, o incentivo à leitura de textos pode ser mais que um meio de motivação, mas também meio de estruturar aulas e de desenvolver habilidades almejadas pela escola.

Almeida, Silva e Babichak (1999), por exemplo, realizaram um estudo sobre alguns aspectos da interação escolar de estudantes do Ensino Médio, focando em seus modos de leitura e argumentação, usando para isso uma atividade relacionada com a física clássica. Durante a pesquisa propuseram aos alunos questões bastante abertas sobre um texto do livro didático envolvendo conceitos científicos. Os pesquisadores perceberam que através da escrita os alunos se manifestaram muito mais do que usualmente. Apesar desse resultado, a análise das respostas indicou dificuldades dos estudantes na compreensão e produção de sentidos para a leitura. Este estudo evidenciou que a compreensão de textos que 
envolvem conceitos científicos nem sempre é óbvia ou simples, assim é preciso trabalhar esse tipo de leitura na escola.

Com relação à Escrita, percebeu-se na literatura da área que ela é mais explorada no Ensino Fundamental, na disciplina ciências (ALMEIDA, 2005; OLIVEIRA, 2001; SOUZA; GIRALDI, 2010). Estes trabalhos evidenciam que a escrita, quando pensada para além de uma ferramenta de reprodução de conteúdos, pode ser meio de produção de sentidos e estímulo à criatividade e ao raciocínio relacionado aos conhecimentos científicos.

Os trabalhos que estudam a escrita de textos no Ensino Médio são menos frequentes, se comparados aos que estudam a leitura. Charret e Krapas (2008) realizaram um estudo no qual analisam redações de estudantes do 3 o ano do Ensino Médio sobre as Leis de Newton, tendo adotado as teorias de Bakhtin como referencial teórico. Uma atividade foi proposta conjuntamente pelos professores de Física e de Redação. A análise dos textos produzidos foi realizada do ponto de vista linguístico pela professora de redação e do ponto de vista científico pela professora de física. Para as pesquisadoras a atividade se constituiu em uma maneira de conhecer o discurso do aluno, permitindo ligações entre a linguagem da física escolar e a linguagem cotidiana, e a partir daí o estabelecimento de um diálogo visando à construção do conhecimento. Esse trabalho evidenciou uma possibilidade de usar o processo de escrita nas aulas de física, para além da cópia de informações, e que pode trazer resultados positivos para a aprendizagem de conceitos físicos.

Apesar dos diversos estudos publicados evidenciarem possibilidades e potencialidades do uso da leitura e a escrita de textos no ensino e na aprendizagem de física, muitas vezes os professores se deparam com dificuldades para propor e utilizar esses processos, sejam pelas condições concretas de trabalho na escola, que não concedem tempo e espaço necessários para a reflexão, ou pela cultura das aulas dessa disciplina, focadas nos problemas físicos tradicionais, entre outros motivos. Neste contexto, na sequência serão apresentados estudos desenvolvidos na Formação Inicial e na prática de Professores de Ciências da Natureza.

\section{LEITURA E ESCRITA NA FORMAÇÃO INICIAL E NA PRÁTICA DE PROFESSORES}

Segundo a teoria de Vigotski, o contexto cultural é uma das principais influências no desenvolvimento humano e a interação social dentro deste contexto cultural possibilita criar formas de agir no mundo. Acredita-se assim que a forma de utilização da leitura e da escrita na aprendizagem de física durante a formação inicial dos professores possa influenciar no modo como eles, posteriormente, as utilizarão em sala de aula no Ensino Médio.

A maioria dos trabalhos que investiga a leitura e escrita na formação inicial e na prática de professores realiza discussões sobre os sentidos atribuídos pelos docentes para a leitura de textos, sendo a escrita ainda pouco estudada. A forma de utilização dessas práticas por esses professores na sua própria aprendizagem de física, enquanto alunos de graduação, também é pouco explorada na literatura. Os trabalhos encontrados fazem inserções de leituras em algumas disciplinas da graduação e algumas análises da relação que os alunos estabeleceram com essas leituras mais pontuais. 
Por exemplo, alguns trabalhos, através de investigações com estudantes de graduação, investigaram a possibilidade de utilização da leitura de textos no curso de Licenciatura em Física (ALMEIDA; SORPRESO, 2010; PEREIRA; OSTERMANN, 2010; ZANOTELLO; ALMEIDA, 2013). Estes estudos defendem que a leitura de textos durante a formação do professor auxilia a fortalecer os conhecimentos, além de motivar a aprendizagem e o hábito de procurar textos e leituras para além do livro didático, futuramente, enquanto professores da Educação Básica.

O trabalho de Zanotello e Almeida (2013) alerta que também no Ensino Superior "o uso da divulgação científica precisa ser planejado, considerando-se os objetivos do ensino, os conteúdos a serem cumpridos e a carga horária da disciplina" (p.129). Assim, usar a leitura e a escrita de textos tanto na Educação Básica quanto no Ensino Superior exige planejamento e reflexão sobre esses processos.

Andrade e Martins (2004), por sua vez, analisaram o discurso de professores de Física, Química e Biologia da Educação Básica sobre a leitura de textos em suas aulas, tendo como referencial teórico a Análise do Discurso (AD) de linha francesa. Segundo o estudo,

\begin{abstract}
A imagem que a maioria dos professores possui deles mesmos é a de um mediador que através da interação irá estabelecer a relação entre textos e alunos. No entanto, esses mesmos professores não se vêem como formadores de leitores. Apesar de valorizarem a utilização de textos com seus alunos, os professores descrevem grandes dificuldades que estes possuem com a leitura e a interpretação e os consideram como não-leitores (ANDRADE; MARTINS, 2004, p. 15).
\end{abstract}

Os resultados indicaram que, segundo os professores participantes, na formação inicial não há espaço de reflexão sobre o papel da leitura no ensino de Ciências, fato que reflete nas suas dificuldades para a inserção deste tipo de atividade em suas aulas.

O trabalho desenvolvido por Assis e Carvalho (2008) analisou a postura de dois professores de física na Educação de Jovens e Adultos (EJA) e no Ensino Fundamental, em atividades que envolviam a leitura de textos paradidáticos. Os autores defenderam que muitas vezes a postura do professor não favorece a aprendizagem significativa. Esse estudo mostrou a insegurança de alguns professores na adoção da leitura de textos em sala de aula, o que fez com que frequentemente permanecessem na superficialidade dos conceitos, não viabilizando a articulação necessária para a aprendizagem. É preciso considerar que esses problemas são mais profundos e têm relação com a formação dos professores e com a visão sobre o que é ensinar física.

Leite (2008) investigou os sentidos e concepções dos professores de física quando realizam atividades de leitura de textos em suas aulas, discutindo as possibilidades e dificuldades por eles apontadas. Os professores que fizeram parte da investigação responderam a um questionário, desenvolveram uma atividade em sala de aula utilizando um texto indicado pelo pesquisador e finalmente, participaram de uma entrevista. Alguns professores destacaram a necessidade de receberem orientações sobre como deveriam ser realizadas as atividades de leitura em sala, pois eles enfrentam dificuldades para desenvolver atividades desta 
natureza, tanto pelas dificuldades dos alunos quanto pela necessidade de um "método adequado".

Finalmente, Almeida (2014) discute a possibilidade de deslocamento no imaginário de licenciandos em física sobre o funcionamento de textos de divulgação científica no Ensino Médio por meio de mediações realizadas em uma disciplina pedagógica de um curso de física. Ao analisar seus discursos, depois das mediações, o estudo conclui que

Determinadas posições de alguns licenciandos, que cursavam a disciplina na qual o estudo foi realizado, não se relacionavam às mediações que havíamos desenvolvido nas condições de produção que haviam sido programadas. Para que isso ocorresse seriam necessárias outras mediações, ou é possível, inclusive, que não viesse a ocorrer (ALMEIDA, 2014, p.185).

Segundo Almeida (2014) o fato dos professores trabalharem efetivamente com textos de divulgação científica depende também das condições de produção que tiverem para preparar suas aulas (p.185).

Carvalho e Gil Pérez (2001) ao discutir a formação inicial de professores colocaram que as pesquisas nesta área indicavam que um dos obstáculos para o professor adotar novas práticas são as ideias docentes de senso comum. Segundo esses autores,

Essas pesquisas (Gené e Gil, 1987; Hewson e Hewson, 1988; Abib, 1997; Adams e Krockover, 1997; Beach e Pearson, 1988) mostram que os professores têm idéias, atitudes e comportamentos sobre o ensino, formados durante o período em que foram alunos, adquiridos de forma não-reflexiva, como algo natural, óbvio, escapando, assim, à crítica e se transformando assim em um verdadeiro obstáculo para uma mudança didática (CARVALHO; GIL PÉREZ, 2001, p. 111).

Talvez isso também ocorra com os processos de leitura e escrita de textos. Por falta de um espaço para a reflexão sobre a temática, eles são usados sem uma crítica, passando despercebidos quanto à sua potencialidade para o ensinoaprendizagem. É preciso refletir para buscar formas de utilização que explorem o potencial desses recursos não somente como uma ferramenta, mas como um meio de construção de conhecimentos e aprendizagem.

As dificuldades com as quais professores de física se deparam ao utilizar a leitura de textos enfatizam a necessidade de repensar as condições das aulas da disciplina e dar atenção aos momentos de formação, tanto inicial quanto continuada, que tratam da temática. 0 primeiro passo pode ser compreender a percepção dos estudantes de licenciatura sobre a leitura e a escrita de textos de modo a ter um ponto de partida para essas discussões e buscar caminhos que possibilitem superar possíveis obstáculos enfrentados por esses futuros professores, para "inovar" no modo de utilização dessas práticas em suas aulas.

\section{REFERENCIAL TEÓRICO: O QUE SE ENTENDE POR LER E ESCREVER}

Vigotski realizou estudos para entender a inter-relação entre o pensamento e habilidades de leitura e escrita. Para ele, entender o desenvolvimento intelectual 
dos indivíduos requer compreender essa inter-relação, pois a linguagem é mais do que a expressão do pensamento, é por meio dela que ele é formado.

Assim como no reino animal, nos seres humanos "o pensamento e a palavra não são ligados por um elo primário" (VIGOTSKI 2008, p.149), ou seja, pensamento e fala têm raízes distintas e suas trajetórias de desenvolvimento não são paralelas. Assim, no decorrer da evolução humana, em certo ponto da trajetória de desenvolvimento, pensamento e fala se encontram, surgindo o pensamento verbal e a fala racional ou intelectual.

Ao propor a expressão dos conhecimentos pela escrita, é preciso considerar que a palavra na fala interior é uma função por si própria e está repleta de sentido, o que torna a sua expressão na fala exterior um ato complexo. Para Vigotski, na fala interior "uma única palavra está tão saturada de sentido, que seriam necessárias muitas palavras para explicá-las na fala exterior" (VIGOTSKI, 2008, p. 183), ou seja, essa transição, da fala interior para a exterior, não é um simples processo de tradução entre as linguagens, mas exige a criação de suportes expressivos e situacionais.

A escrita exige que a atividade da fala assuma formas complexas, pois estão ausentes os suportes situacionais e expressivos do diálogo face a face, gerando a necessidade dos rascunhos que refletem o processo mental. Segundo Vigotski,

\footnotetext{
O planejamento tem um papel importante na escrita, mesmo quando não fazemos um verdadeiro rascunho. Em geral, dizemos a nós mesmos o que vamos escrever, o que já constitui um rascunho, embora apenas em pensamento. [...] esse rascunho mental é uma fala interior (VIGOTSKI, 2008, p.179/180).
}

O incentivo à escrita como meio de produção de conhecimentos nas aulas de física pode ser importante no estímulo e desenvolvimento desse processo mental de elaboração de rascunhos, por meio do qual o pensamento se torna mais concreto. A escrita como uma atividade intelectual pode viabilizar não só ao professor certo acompanhamento da aprendizagem, por a escrita ser uma forma de expressão, mas principalmente possibilita ao aluno tornar-se mais consciente sobre o seu ato de pensamento, pela estruturação das suas ideias e de conceitos. É importante considerar que "o pensamento não é simplesmente expresso por palavras; é por meio delas que ele passa a existir" (VIGOTSKI, 2008, p.157).

O processo de leitura de textos escritos também não é simples, pois esses podem adquirir vários sentidos dependendo de quem os produz ou os interpreta. "Assim como uma frase pode expressar vários pensamentos, um pensamento pode ser expresso por meio de várias frases" (VIGOTSKI, 2008, p.186), isso porque a escrita é um processo dinâmico e as palavras assumem sentidos a partir da interação do leitor com o texto.

Ao usar a leitura e a escrita no ensino de física é preciso refletir sobre os diferentes sentidos que atividades que envolvem esses processos podem proporcionar aos estudantes.

Nascimento (2013), pautado na teoria de Vigotski, afirma que "escrever e ler, cada um a seu modo, mobiliza a percepção dos sujeitos autores e leitores" (p. 450), pois o domínio e uso dessas práticas proporcionam uma reorganização do pensamento. Nesse sentido, a leitura e a escrita nas aulas de física podem ser 
ferramentas de aprendizagem na construção do conhecimento pelo estudante, além da possibilidade de, por meio dessas práticas como forma de produção, incentivar a imaginação e criatividade dos estudantes no estabelecimento e expressão de relações de sentidos particulares.

Para Vigotski, a aprendizagem de conceitos e desenvolvimento da comunicação por meio da leitura e da escrita ocorre pelo contato e necessidade de uso em situações reais. Para ele, a criança não aprende a língua materna através do alfabeto e das normas da escrita, mas na sua "usualidade" (RIOS, 2006). O signo é um instrumento usado na interação social entre os homens e, portanto, aprendido no meio cultural em situações de comunicação verbal.

Vigotski (2008) propõe que um conceito é o significado de uma palavra, e seu desenvolvimento, mais do que um simples hábito mental, é na verdade um ato real e complexo de pensamento que pressupõe o amadurecimento de muitas funções intelectuais como a abstração, atenção deliberada, memória lógica e capacidade de comparar e diferenciar (p.104).

É importante considerar ainda que a fala possui motivos paralelos e "uma compreensão plena e verdadeira do pensamento de outrem só é possível quando entendemos sua base afetivo-volitiva" (VIGOTSKI, 2008, p. 187), ou seja, a sua motivação, que advêm de seus interesses, necessidades, desejos e emoções. Ao analisar a fala ou a escrita do outro é preciso considerar que fatores subjetivos e sócio-históricos influenciam no seu pensamento e forma de expressão.

\section{METODOLOGIA}

Com o intuito de compreender a importância que estudantes de um curso de Licenciatura em Física atribuem à leitura e escrita na sua formação inicial, bem como a importância e as dificuldades para seu uso no ensino de física na Educação Básica, foi elaborado um questionário, que foi respondido por oito estudantes de uma universidade pública, no contexto da disciplina Metodologia do Ensino de Física, que compõe o 4 período do curso, de um total de nove períodos.

Tal disciplina busca, dentre diversos objetivos, discutir questões referentes ao papel das diferentes linguagens no ensino de física. O questionário foi respondido antes de serem realizadas discussões sobre a leitura e a escrita de textos no ensino.

No contexto da disciplina, o objetivo do questionário utilizado era que os licenciandos pudessem, previamente às discussões que se seguiriam nas próximas aulas, refletir sobre como a leitura e a escrita se relacionam com suas próprias formas de aprender física no Ensino Superior, e as possibilidades para o ensino e aprendizagem de física no Ensino Médio.

Antes que os estudantes respondessem o questionário, foi esclarecido que tal instrumento tratava-se de uma estratégia no âmbito da disciplina, mas que havia também a intenção de utilizá-lo para fins de pesquisa. Caso o estudante permitisse que suas respostas fossem utilizadas no âmbito da pesquisa, solicitou-se que assinasse um Termo de Consentimento autorizando que suas respostas fossem utilizadas com tal fim. Caso ele não permitisse, suas respostas seriam utilizadas apenas no âmbito da disciplina, sem que isso acarretasse quaisquer interferências 
(positivas ou negativas) em sua avaliação semestral. Todos os alunos concordaram com os termos de participação na pesquisa.

O questionário possuía ao total 14 questões, a maioria dissertativa, dividida em três eixos principais.

Através do primeiro eixo busca-se compreender o perfil do estudante com relação à sua formação; à sua atuação profissional como professor e em projetos de extensão universitária. Composto de quatro questões, o intuito é saber qual o contato do aluno, até então, com discussões e reflexões relacionadas à temática, devido às suas experiências acadêmicas e profissionais. Assim, conhecendo suas motivações e vivências pessoais (VIGOSTKI, 2008), será possível se aproximar de sua compreensão sobre o uso das práticas de leitura e escrita.

Através do segundo eixo busca-se compreender a percepção do aluno enquanto professor (ou futuro professor) de física. Foram utilizadas quatro questões: duas se referiam à utilização da leitura e duas se referiam à escrita de textos no ensino e na aprendizagem de física no Ensino Médio. Uma dessas questões deveria ser respondida na condição do estudante já haver planejado aulas de física utilizando a leitura de textos - como professor ou estudante em disciplinas pedagógicas na graduação. Essa questão se referia às vantagens e limitações enfrentadas para usar a leitura. O intuito é compreender, pela percepção dos estudantes, a importância do estímulo à leitura e escrita sobre ciência junto aos alunos do Ensino Médio, bem como as possibilidades e as dificuldades na sua utilização.

Com o terceiro eixo do questionário busca-se compreender a percepção dos respondentes sobre a leitura e escrita de textos em sua própria aprendizagem de física, como estudantes de graduação que são. Foi composto por seis questões: três se referiam à utilização da leitura e três se referiam à escrita de textos no Ensino Superior.

Com esse conjunto de questões busca-se compreender as percepções dos estudantes sobre a presença da leitura e escrita de textos em sua aprendizagem de física no Ensino Superior, suas percepções sobre a leitura e escrita de textos no ensino-aprendizagem física no Ensino Médio e possíveis relações entre elas. Analisam-se as percepções desses estudantes sobre essas práticas, tecendo reflexões à luz da teoria de Vigotski (2008).

\section{DISCUSSÃO E ANÁLISE DOS RESULTADOS}

Assim como o questionário, a análise está organizada em três partes. $\mathrm{Na}$ primeira é apresentado o perfil dos participantes, na segunda discute-se, a partir da percepção dos estudantes, sobre como essas práticas estão ou não presentes no seu curso de graduação e na terceira, exploram-se as suas visões em relação às possibilidades da leitura e da escrita em aulas de Física no Ensino Médio.

\section{QUANTO AO PERFIL DOS ESTUDANTES PARTICIPANTES}

A maioria dos oito estudantes que responderam o questionário está quase na metade da graduação e dois deles já atuam como professores na Educação Básica. 
Cinco alunos possuem outra formação profissional anterior (curso técnico ou de graduação) não ligada à Educação, sendo que três deles atuam profissionalmente nessa primeira área de formação.

Apenas dois estudantes participam de projetos de extensão na universidade. Os projetos de extensão podem oferecer aos alunos experiências que nem sempre são proporcionadas nas disciplinas do curso, assim conferindo aos alunos mais um espaço para a discussão de problemas e propostas para a docência em Física, além de apoio e acompanhamento no início da trajetória profissional.

A maioria desses estudantes ainda não teve um contato com a sala de aula como professor. É possível que algumas disciplinas pedagógicas cursadas no início da graduação possam ter proporcionado discussões sobre a utilização de diferentes linguagens e recursos no ensino de física, mas provavelmente muitas das percepções apresentadas por esses estudantes no questionário estão ligadas à sua vivência enquanto alunos na Educação Básica ou na graduação. Apenas dois estudantes afirmaram atuar como professores no Ensino Médio, mas, mesmo esses apontam que nunca, durante a graduação ou em sua atividade profissional, propuseram atividades de leitura ou escrita para ensinar física.

No Quadro 1 é feita uma síntese do perfil de cada estudante em relação ao curso e experiências como professor na Educação Básica.

Quadro 1 - Informações dos estudantes que responderam ao questionário

\begin{tabular}{|c|c|c|c|c|}
\hline Aluno & $\begin{array}{c}\text { Período que } \\
\text { está } \\
\text { cursando }\end{array}$ & $\begin{array}{l}\text { Possui outra } \\
\text { formação } \\
\text { anterior? }\end{array}$ & $\begin{array}{l}\text { Atua ou atuou } \\
\text { como professor } \\
\text { na Educação } \\
\text { Básica? }\end{array}$ & $\begin{array}{l}\text { Participa ou Participou } \\
\text { de Projetos de } \\
\text { Extensão? }\end{array}$ \\
\hline A1 & 50 & Sim & Não & Não \\
\hline$A 2$ & $\begin{array}{c}\text { Sem } \\
\text { resposta }\end{array}$ & Não & Não & Não \\
\hline A3 & 40 & Sim & Não & Não \\
\hline A4 & 40 & Não & Não & Sim \\
\hline A5 & 40 & Sim & Não & Não \\
\hline A6 & 40 & Não & Não & Sim \\
\hline A7 & 9으 & Sim & Sim & Não \\
\hline A8 & 40 & Sim & Sim & Não \\
\hline
\end{tabular}

Fonte: Autoria própria (2017)

Em relação ao hábito de leitura dos estudantes, ressalta-se que eles possuem a leitura presente em seu cotidiano, seja na internet, livros ou nos textos relacionados ao curso da universidade. Dois alunos (A1 e A2) fizeram menção apenas às leituras relacionadas com o curso de graduação: livros, artigos ou sites de física/ciência. Os outros seis alunos mencionaram, além das já relacionadas, outras leituras que não estão diretamente ligadas ao curso de física (livros, sites, notícias, bíblia, entre outros).

Não é possível fazer uma generalização sobre a importância da leitura no além daquelas solicitadas no curso de graduação. É algo subjetivo para cada um e 
que também, de alguma forma, pode ter influenciado nas suas respostas às questões.

Em relação à escrita no cotidiano, $A 6, A 7$ e $A 8$ disseram que escrevem em atividades referentes à graduação: resumos, relatórios, relatos, entre outros, assim como A2 e A4 mencionaram usar a escrita para aprender e sistematizar conceitos nas disciplinas. Os alunos A1 e A3 explicitam que apenas escrevem quando é necessário e o estudante A5 mencionou usar a escrita no seu trabalho e também para anotações em um diário. Desta forma, percebe-se que a escrita também se faz presente no cotidiano destes alunos, porém de modo mais limitado se comparada à leitura de textos, já que é utilizada essencialmente em atividades da graduação.

Talvez esse perfil dos estudantes possa justificar que para alguns seja mais fácil discutir e concordar com a importância e possibilidades das leituras de textos para a aprendizagem de física, se comparada à utilização da escrita, já que aquela parece ser uma prática que a maioria tem maior contato e gosto em seu dia a dia.

\section{QUANTO A LEITURA E A ESCRITA DE TEXTOS NA APRENDIZAGEM DE FÍSICA - ENSINO SUPERIOR}

Para compreender a percepção dos sujeitos sobre sua própria experiência de aprendizagem de física através da leitura e da escrita, questionou-se sobre a presença dessas práticas na formação inicial desses estudantes. Enquanto alunos de um curso de graduação, eles usam a leitura e a escrita de textos para aprender física? De que forma? Essas respostas podem relacionar-se com o modo como estes estudantes virão a conceber esses processos na sala de aula enquanto futuros professores.

Segundo os estudantes, pelas respostas ao questionário, as disciplinas da Licenciatura em Física exigem leituras, principalmente de livros didáticos e artigos científicos. Os textos são algumas vezes apenas indicados aos alunos, ficando a leitura a critério de cada um.

Os estudantes fizeram alguns apontamentos em defesa de que a leitura de textos auxilia na aprendizagem de física durante o curso de graduação.

Para A1 "é muito mais fácil ler do que interpretar uma fórmula matemática", para A4 pela leitura é possível "... ter uma visão mais geral do conceito físico e não apenas fórmulas" e A2 coloca que com a leitura "aprendemos o conceito e não só a calcular".

Na questão sobre como a leitura é usada/estimulada na graduação, o aluno A2 ressaltou que nas "matérias de metodologia [do ensino de física] nos ensinam muitas vezes, através da leitura, conceitos físicos, que não bem aprendemos nas físicas teóricas, por talvez não lermos os conteúdos, antes, depois ou durante essas aulas". Essa fala ressalta que muitas vezes a ênfase nas operações matemáticas pode levar a reprodução mecânica de exercícios sem a sua devida compreensão, e que as disciplinas de Metodologias de Ensino, por incentivarem a leitura dos conteúdos, os levam a aprender inclusive os conteúdos das "físicas teóricas", nas palavras do próprio aluno. 
Numa perspectiva semelhante, para A5, "artigos técnicos podem ajudar a ilustrar o fenômeno ou conceito estudado, quando apenas equações carecem de visualização".

O aluno A6 também coloca que a leitura contribui no aprofundamento dos conteúdos estudados. Segundo ele, após a aula do professor ele ainda sente necessidade de um "estudo mais delicado e detalhado. Nessa hora leio o livro didático para rever o que foi visto em sala e até para acompanhar cálculos mais detalhados, ou demonstrações".

Todos esses apontamentos parecem convergir para um mesmo ponto: a leitura proporciona uma melhor compreensão conceitual da física. Conforme discutido em pesquisas da área, a leitura, além dos textos técnicos, pode ser usada também com outras finalidades como motivação, problematização, interdisciplinaridade, entre outros.

O estudante A3 considera que a leitura e a escrita de textos “... não deve(m) ser tomado(s) como único instrumento de aprendizagem...". Saber física não é só resolver exercícios que envolvem operações matemáticas. Saber física também é interpretar, criar, buscar e compreender informações e vocabulários específicos. Assim como o aluno A3 ressalta que a leitura não deve ser o único instrumento, ela também não pode deixar de ser um.

Não é possível inferir a partir das respostas ao questionário a exata percepção de leitura desses estudantes. Porém, a maioria valoriza essa prática na sua aprendizagem conceitual de física, parecendo uma concepção de leitura mais técnica e com um sentido dado a priori no próprio texto. O texto científico busca diminuir a ambiguidade pelo uso de suportes situacionais, mas mesmo assim é preciso refletir sobre o processo de interação entre leitor e texto (VIGOTSKI, 2008) que continua ocorrendo e que pode gerar diferentes sentidos ao mesmo texto.

Em relação à escrita, as respostas dos estudantes indicam que ela está presente na produção de relatórios experimentais, do caderno de laboratório e/ou a cópia de conceitos físicos. O motivo mais citado para justificar o auxílio na aprendizagem foi a necessidade de síntese e memorização/fixação de informações.

O uso da escrita também foi mencionado para a reflexão sobre o conteúdo, em geral associada à memorização. Para A2, por exemplo, a escrita não deve ser apenas cópia e deve ser usada "desde que o conteúdo saia das experiências do aluno, como por exemplo, conclusão e comentários feitos por ele próprio levandoo a refletir e memorizar o assunto". Ainda que mencione a memorização, nesta resposta de $\mathrm{A} 2$ observa-se um indício de que ele concebe a necessidade de que a escrita seja pautada em uma autoria, quando menciona "conclusões e comentários feitos por ele próprio".

Para A5, a escrita "facilita em especial a memorização do assunto, além de estimular o entendimento correto, necessário para produzir um texto". Para A7, "a cópia do quadro ajuda a gravar o conteúdo". O aluno A8 também considera que ela auxilia "como agente de fixação de conteúdo e nos obriga a pensar mais de quando falamos".

A concepção de escrita de alguns estudantes parece limitada a uma ferramenta de fixação/memorização de conteúdos. Mais do que isso, a escrita 
pode promover o processo de estruturação e organização de ideais e, portanto, a aprendizagem dos conceitos.

Vigotski (2008) discute que a fala oral precede o desenvolvimento da fala interior, enquanto que a escrita segue e pressupõe a sua existência (p. 124). Nesse sentido escrever exige mais do indivíduo, sendo uma atividade mais complexa, percepção expressa, de certa forma, na resposta de A8, que diz que a escrita "nos obriga a pensar mais de quando falamos".

Por outro lado, A7 também considera que a "a escrita "própria" obriga a organizar as ideias para colocá-las no papel", abordagem das "matérias de física experimental", se aproximando da concepção de que escrever pode ser uma ferramenta de aprendizagem no Ensino Superior.

O aluno A6 enxerga a escrita essencialmente como um meio de expressar o conhecimento para que possa ser avaliado pelo professor. Segundo ele, "preciso escrever para mostrar o que aprendi com respostas a perguntas conceituais e relatórios".

Dessa forma, no Ensino Superior enquanto a leitura parece vir associada a uma aprendizagem conceitual (não incluindo aí a matemática), a escrita parece ter uma forte relação com a memorização. Muitas vezes, as anotações escritas são feitas caso seja importante e necessário lembrar aquele conceito posteriormente. Parece que não é comum pensar a escrita como produção/construção de um conhecimento, mas como um registro de informações. Embora entre os alunos haja outras concepções mais amplas sobre a escrita, tais como as mencionadas por A7 e A8, essas foram mais escassas, o que ressalta a importância de discutir na formação inicial desses professores a potencialidade deste recurso.

\section{QUANTO A LEITURA E A ESCRITA DE TEXTOS NAS AULAS DE FÍSICA - ENSINO MÉDIO}

Buscou-se também compreender como estes futuros professores concebem a utilização da leitura e escrita para ensinar física no Ensino Médio.

Entre os estudantes que responderam o questionário parece haver consenso de que a leitura é importante para o ensino/aprendizagem de física no Ensino Médio. Já com relação à escrita, embora concordem que possa ser usada, parece não ser tão significativa como a prática de leitura.

Os motivos apresentados pelos estudantes para a importância de ler textos de física foram: Melhor aprendizagem conceitual ( $A 1, A 5$ e A6), desenvolver o hábito da leitura e a capacidade de interpretação de textos (A2 e $A 5$ ) e incentivar o aluno a buscar informações e conhecimentos (A3).

O aluno A2 considera "válido" a utilização da leitura de textos "caso haja uma linguagem adequada (fácil compreensão) para que todos possam entender o que está escrito nele". Percepção semelhante de A8 que afirma que é válido "desde que sejam textos não formais, de modo que qualquer pessoa possa lê-los. Esses textos deverão provocar curiosidade científica no leitor".

A física tem uma linguagem específica e, portanto, a leitura e compreensão de textos relacionados a este campo de conhecimentos requer a compreensão de 
determinados conceitos e vocabulários, que devem ser trabalhados no processo de escolarização. Como ressalta Vigotski (2008) a aprendizagem de novos conceitos não ocorre pela memorização, mas pela necessidade e usualidade desses conceitos. Se essa aproximação entre alunos e textos nunca for promovida, dificilmente o aluno dará sentido a esse tipo de atividade também na sua vida cotidiana. Bakhtin (1992), por exemplo, discute que um enunciado necessita do outro para existir, ou seja, todo enunciado é elaborado e estruturado tendo em vista o fundo aperceptivo de um interlocutor. Concebendo textos de física como enunciados é preciso considerar para quem o texto se dirige. Nesse sentido, textos da esfera científica talvez não sejam adequados para serem trabalhos na Educação Básica, se comparados àqueles que consideram o nível de conhecimento dos estudantes. Porém, na Educação Básica também é importante não só trabalhar com textos que estejam em uma linguagem de "fácil compreensão" (utilizando as palavras de A2), mas também com textos que utilizem outras linguagens, não comuns, para que se possa promover essa aproximação e desenvolver novos hábitos e conhecimentos.

Para A7, que já atua como professor na Educação Básica, "os alunos que têm boa memória visual saem-se bem com esta abordagem. Já os que têm memória auditiva encontrarão dificuldades". Acredita-se que os alunos precisam desenvolver diferentes habilidades com a escolarização, e neste sentido ler é importante não só para aqueles que têm facilidade, mas principalmente para os que têm dificuldades, visto que a partir da leitura é possível aprender e passar a apreciá-la. Vigotski (2008) defende que o desenvolvimento de novos conceitos ocorre pela necessidade e usualidade desses, o que permite interpretar que devem ser proporcionadas situações em sala de aula que torne a leitura de textos, que envolvem física, necessária e significativa, dentro do contexto de aprendizagem.

Apenas dois estudantes disseram que durante a graduação planejaram aula(s) em que utilizaram a leitura de textos e apontaram reflexões sobre as vantagens e desvantagens com esta prática.

Uma das dificuldades apontadas é que o aluno "não será cobrado somente ou com grande peso nessa parte e sim através da matemática" (A1). Por mais que alguns professores busquem fazer um trabalho diferenciado em sala de aula utilizando a leitura, muitas vezes na avaliação exige dos alunos apenas a resolução de exercícios com operações matemáticas. Não significa que isto não incentive a leitura em sala de aula, mas de algum modo pode passar aos alunos uma mensagem implícita de uma atividade de menor valor, ao não serem trabalhadas também nos processos avaliativos. Neste sentido é preciso problematizar também questões relacionadas à Cultura Escolar (FORQUIN, 1993) para que seja possível ampliar compreensões sobre métodos, estratégias e objetivos do ensino de Física, sempre associados à discussão dos processos avaliativos.

Outra dificuldade apontada é "quando utilizar, pois o tempo da aula é muito curto" (A4). Se o tempo da aula é curto, estimular a leitura poderia ser algo essencial para despertar o aluno na busca de novos conhecimentos, para além da sala de aula. Porém, talvez a questão seja mais profunda e passe pelos objetivos e sentido da escolarização, que requer pensar numa seleção de conteúdos.

Quanto à escrita de textos em aulas de física, três estudantes (A2, A4 e A5) consideram que a prática não é comum, mas é utilizada nas provas e questionários, 
quando não há "problema numérico" (A2), ou seja, em "questões mais teóricas e também nos relatórios de aulas práticas" (A5). A7 menciona a escrita em aulas com foco mais conceitual, dependendo do professor. Para A8, os alunos não são estimulados e não escrevem em aulas de física.

Para A3 "... o aluno deve ser estimulado a pensar. Escrever fica a critério dele".

Assim a escrita, pela percepção desses estudantes, está (ou pode estar) presente nas aulas de física, mas não é essencial para a aprendizagem. Ela auxilia sendo mais uma prática entre outras, sendo utilizada em determinados momentos e com certos objetivos.

Quanto às possibilidades de sua utilização para ensinar física na Educação Básica, seis estudantes afirmaram que a usariam em sala de aula. Dois alunos disseram que poderiam utilizá-la, solicitando que os alunos escrevessem um texto sobre o que entenderam do conteúdo trabalhado (A1 e A4): "assim poderia perceber quais pontos o aluno considera mais importante e quais ele assimilou com clareza" (A4).

A percepção desses alunos se aproxima da concepção da escrita pelo viés de um veículo de comunicação pedagógica (CARVALHO; BARBEIRO, 2013). Isso ressalta a necessidade da formação inicial proporcionar discussões sobre a escrita no processo de aprendizagem de forma a ampliar a compreensão da escrita por outros vieses.

Outros disseram que a utilizariam para os alunos explicarem "fenômenos com suas próprias palavras" (A2) ou então "relacionando os fenômenos cotidianos aos conceitos estudados em sala" (A5). O aluno A7 propõe que pode ser usada para "aprimorar e fixar conceitos" já que a escrita requer uma organização de tais conceitos. As perspectivas desses alunos sobre a escrita parecem considerar a contribuição desse processo na aprendizagem, portanto se aproximando da ideia de uma ferramenta de aprendizagem (CARVALHO; BARBEIRO, 2013), que é possível associar à concepção de escrita em Vigotski, como um processo onde são estabelecidas relações de sentidos e o pensamento torna-se mais estruturado e, portanto, concreto.

A3 afirmou que não usaria a escrita porque, segundo ele, ela "... é um dos modos de refletir o pensamento, mas não é o único. 0 modo de refletir o pensamento deve ser escolha do aluno", reforçando que a escrita é mais um instrumento/recurso entre outros. É interessante refletir sobre esta expressão de A3, que menciona a possibilidade de escolha do aluno pelos modos para refletir seu pensamento. Novamente resgata-se aqui a cultura escolar (FORQUIN, 1993) do ensino de física, pois aos alunos raramente é dada a possibilidade de escolha ou incentivada novas formas no "modo de refletir o pensamento". Em aulas de física, habitualmente, problemas e exercícios são as formas predominantes de expressão de conhecimento. Talvez, contraditoriamente, se a possibilidade de escolha fosse uma prática mais comum nas aulas de física, a escrita pudesse ser mais frequente em sala, talvez por iniciativa dos alunos. O aluno A6 também considera que a física pode ser "ensinada de maneira diferente" já que "parece ser parecido com o que é feito em diversas outras matérias".

Em relação à escrita no Ensino Médio, a forma de utilização descrita pelos estudantes participantes nesta parte do questionário não é muito diferente de suas experiências no uso desses processos em suas aprendizagens de física, como 
alunos que são no Ensino Superior. Ou seja, parece que a forma com que eles concebem a utilização desses processos na Educação Básica acaba sendo semelhante à experiência que eles têm com a aprendizagem de física como alunos na graduação, a diferença é o aprofundamento do conteúdo de física que é ensinado/aprendido.

Talvez propor a escrita de textos em aulas de física seja mais difícil do que propor a leitura, pois falar em escrita pode remeter a um trabalho manual. Os estudantes vivem cercados de tecnologias onde a escrita autoral tende a ser cada vez menos utilizada e a cópia de textos em formatos digital cada vez mais fácil e comum.

Quando se propõe a escrita de textos, conforme os exemplos citados pelos quatro estudantes, ela acaba sendo uma cópia ou um relatório ao final de uma atividade. Oliveira (2001) ressalta a necessidade de se dar mais atenção ao processo e não apenas ao produto final da escrita. Para isso é importante que os educadores reflitam sobre o seu uso como processo de construção. A ideia não é substituir as operações matemáticas e tornar esse o único "modo de reflexão", como colocou o aluno A3, mas trabalhar em conjunto as diversas abordagens para tornar possível que o aluno desenvolva diferentes habilidades, aprendendo através da construção dos conhecimentos e não de sua reprodução não compreensiva.

\section{CONSIDERAÇÕES FINAIS}

As percepções que os alunos demonstraram acerca da importância da leitura e da escrita de textos para a aprendizagem de física, tanto no Ensino Médio quanto no Ensino Superior, parecem estar associadas às suas experiências enquanto alunos, o que é comum segundo pesquisas apontadas por Carvalho e Gil Pérez (2001) e, dependendo do contexto, pode se constituir em um obstáculo na formação desses professores.

Conhecer as percepções que estudantes dos cursos de Licenciatura em Física atribuem para a leitura e a escrita de textos é um importante ponto de partida para se pensar na formação desses graduandos de modo a propor estratégias para ampliar suas concepções acerca desses processos, extrapolando os limites frequentemente colocados pelo seu uso restrito em sala de aula.

As respostas ao questionário mostram que, para os estudantes participantes, a leitura de textos é importante na sua formação principalmente por proporcionar uma melhor compreensão conceitual da física, mas, ainda assim, as possibilidades de sua utilização em aulas de física acabam sendo limitadas e muitas vezes se resumem à complementação de explicações e atividades desenvolvidas em sala.

Quanto à escrita, apesar de presente tanto no Ensino Superior quanto no Ensino Médio, pelas afirmações dos alunos participantes ela parece ser mais limitada em sua utilização do que a leitura de textos. A escrita é frequentemente vista como reprodução através do simples registro de informações ou elaboração de relatórios. Com os avanços tecnológicos que facilitam o acesso às informações, muitas vezes, tem-se a impressão de não ser necessário o registro escrito pessoal, o que pode gerar a falsa sensação de que escrever não auxilia na construção dos conhecimentos pelo estudante. 
Aceitar que a escrita possa ser um meio de construção do conhecimento em física parece algo menos plausível para estes estudantes de graduação e que, portanto, exige discussões aprofundadas. É preciso refletir e discutir com os estudantes o que significa escrever. Apesar de a escrita ser usada para este fim, é preciso superar a ideia de seu uso apenas para a memorização de conceitos, ou expressão dos conhecimentos para ser avaliado pelo professor, citados nas respostas desses futuros professores. É necessário conceber a escrita como um processo de formulação, organização dos pensamentos, de reflexão e reconstrução e não apenas no trabalho manual de escrita de letras, como compreendido neste estudo a partir de Vigotski. Diferentes teorias referentes à linguagem, como em Bakhtin (1992) ou a Análise de Discurso de linha francesa, usada em trabalhos da literatura da área de ensino de ciências, podem auxiliar a ampliar essas compreensões sobre a leitura e a escrita, com um olhar mais atento as suas condições de produção.

Assim, discussões sobre a leitura e a escrita de textos nos cursos de licenciatura, a partir de diferentes referenciais teóricos, são fundamentais para que os futuros professores possam refletir sobre essas práticas e ampliar suas concepções sobre a sua potencialidade no ensino-aprendizagem de física. Entretanto, como aponta este estudo, parece haver certo reflexo da forma como a leitura e a escrita são utilizadas no Ensino Superior com a forma de pensar essas práticas para ensinar no Ensino Médio. Talvez tão importante quanto inserir tais discussões nas disciplinas "pedagógicas", seja ampliar o modo de utilização destes processos no Ensino Superior, na própria aprendizagem de física destes futuros professores (ou seja, em disciplinas de física), assim ampliando os modos de utilização, explorando as diversas possibilidades que esses processos trazem para a aprendizagem de física e para a formação dos futuros professores. 


\title{
Perceptions of undergraduates of a teaching degree programme about reading and writing in the physics teaching-learning process
}

\begin{abstract}
This article discusses perceptions of undergraduates of a teaching degree programme, about reading and writing in the Physics teaching-learning process. Researches have indicated difficulties that teachers face when using these processes to teach Physics, which can be related to a lack of use of these practices in their initial teacher training. It was analysed answers of eight students to a questionnaire, which was organized in three parts: the first part seeks to access the personal profile of the students; the second one, their perceptions on the use and the importance they attribute to reading and writing in their own Physics concepts learning and in their professional training. Finally, the third part tries to bring up their perceptions on the use of these practices in High School (putting themselves in the role of Physics teacher). Reflections are made in light of Vygostky's theories about reading and writing, assuming them as sociocultural practices. Results indicate that for these future teachers, reading is considered important for learning, mainly by the conceptual understanding that it can provide. Writing texts, in its turn, is understood as an additional resource and is, especially in Higher Education, associated to memorizing information. This study highlights the necessity of extending these future Physics teacher's views about reading and writing, through discussions on these issues during their undergraduation, besides encourage them to use these processes in their Physics learning, as they are still students of the teaching degree programme.
\end{abstract}

KEYWORDS: Reading. Writing. Physics. Physics teachers education. Undergraduate degree. 


\section{AGRADECIMENTOS}

À coordenação de Aperfeiçoamento de Pessoal de Nível Superior (Capes).

\section{REFERÊNCIAS}

ALENCAR ANDRADE, I. B. de; MARTINS, I. Discursos de professores de ciências sobre leitura. In: Encontro de Pesquisa em Ensino de Física - EPEF, 9, 2004, Jaboticatubas Atas... Jaboticatubas: SBF, 2004.

ALMEIDA, M. J. de; O imaginário de Licenciandos em Física sobre o funcionamento de textos de divulgação científica no Ensino Médio. In: SANTOS, B. F. dos; SÁ, L. P. (Org.) Linguagem e ensino de Ciências: ensaios e investigações, ljuí: Ed. Unijuí, 2014. p. 171 - 204.

ALMEIDA, M. J. P. M. de; RICON, A. E. Divulgação Científica e texto literário - uma perspectiva cultural em aulas de Física. Caderno Catarinense de Ensino de Física, v.10, n.1, p. 7-13, abr. 1993. Disponível em: <https://periodicos.ufsc.br/index.php /fisica/article/view/9791>. Acesso em: 19 ago. 2016.

ALMEIDA, M. J. P. M.; SILVA, H. C.; BABICHAK, C. C. O movimento, a mecânica e a Física no Ensino Médio. Revista Brasileira de Ensino de Física, v. 21, n. 1, p.195201, mar. 1999. Disponível em:

<http://www.sbfisica.org.br/rbef/pdf/v21 195.pdf>. Acesso em: 19 ago. 2016.

ALMEIDA, M. J. P. M. de; SILVA, H. C.; MACHADO, J. L. M. Condições de produção no funcionamento da leitura na educação em física. Revista Brasileira de Pesquisa em Educação em Ciências, Porto Alegre, v.1, n.1, jan-abr, 2001. Disponível em: <http://revistas.if.usp.br/rbpec/article/download/212/196>. Acesso em: 19 ago. 2016.

ALMEIDA, M. J. P. M.; SORPRESO, T. P. Memória e formação discursivas na interpretação de textos por estudantes de licenciatura. Revista Brasileira de Pesquisa em Educação em Ciências, v. 10, n. 1, 2010. Disponível em: $<$ http://revistas.if.usp.br/ rbpec/article/viewArticle/12 >. Acesso em: 19 de ago. 2016.

ASSIS, A.; CARVALHO, F. L. de C. A postura do professor em atividades envolvendo a leitura de textos paradidáticos. Revista Brasileira de Pesquisa em Educação em Ciências, v. 8, n. 3, 2008. Disponível em:

$<$ http://revistas.if.usp.br/rbpec/article/view Article/45>. Acesso em: 19 de ago. 2016. 
BAKHTIN, M. Os gêneros do discurso. In: BAKHTIN, M. Estética da criação verbal. São Paulo: Martins Fontes, 1992. p. 277-326.

CARVALHO, J. A. B.; BARBEIRO, L. F. Reproduzir ou construir conhecimento? Funções da escrita no contexto escolar português. Revista Brasileira de Educação, v. 18 n. 54 jul-set. 2013. Disponível em:

<http://www.scielo.br/pdf/rbedu/v18n54/06.pdf>. Acesso em: 19 ago. 2016.

CARVALHO, A. M. P. de; GIL PÉREZ, D. O saber e o saber fazer dos professores. In: CASTRO, A.D. e CARVALHO, A. M. P. (Orgs.) Ensinar a Ensinar: Didática para a Escola Fundamental e Média. São Paulo: Pioneira Thomson Learning, 2001. p.107-124.

CHARRET, H. da C.; KRAPAS, S. O discurso da física escolar como uma linguagem social particular: um olhar sobre a redação dos alunos. In: Encontro de Pesquisa em Ensino de Física - EPEF, 11., 2008, Curitiba. Anais... Curitiba: SBF, 2008.

GIRALDI, P. M. Leitura e escrita no ensino de ciências: espaços para produção de autoria. 2010. 232 f. Tese (Doutorado) - Curso de Pós-Graduação em Educação Científica e Tecnológica, Universidade Federal de Santa Catarina, Florianópolis, 2010.

LEITE, Á. E. Leitura no ensino de física: concepções, sentidos, possibilidades e dificuldades segundo o olhar dos professores. 2008. 128 f. Dissertação (Mestrado) - Curso de Pós-Graduação em Educação, Universidade Federal do Paraná, Curitiba, 2008.

NASCIMENTO, R. de O. Contribuições de Vigotski para se pensar os processos de leitura e escrita na educação escolar. Ensino em Re-vista, Uberlândia, v. 20, n. 2, p.445-460, jul/dez 2013.

OLIVEIRA, O. B. Possibilidades da escrita no avanço do senso comum para o saber científico na 8a série do ensino fundamental. 2001. 163f. Dissertação. (Mestrado em Educação). Faculdade de Educação. Universidade de Campinas, 2001.

PEREIRA, A. P.; OSTERMANN, F. O papel da mediação textual na explicação de futuros professores de física sobre mecânica quântica. In: ENCONTRO DE PESQUISA EM ENSINO DE FÍSICA - EPEF, 12., 2010, Águas de Lindóia. Anais... Águas de Lindóia: SBF, 2010. 
RIOS, E. N. Bakhtin e Vigotski: reflexões sobre o ensino da língua materna.

APRENDER - Cad. de Filosofia e Psic. da Educação, Vitória da Conquista; Ano IV, n. 7, p. 67-88, 2006.

SILVA, H. C. Como, quando e o que se lê em aulas de física no ensino médio: elementos para uma proposta de mudança. 1997. Dissertação (Mestrado em Educação). Faculdade de Educação. Universidade Estadual de Campinas, 1997.

SOUZA, S. C. de; ALMEIDA, M. J. P. M. de. Escrita no Ensino de Ciências: Autores do Ensino Fundamental. Ciência \& Educação, v. 11, n. 3, p.367-382, 2005. Disponível em: <http://www.scielo.br/pdf/ciedu/v11n3/02.pdf>. Acesso em: 19 ago. 2016.

VIGOTSKI, L. S. Pensamento e linguagem. 4. ed. São Paulo: Martins Fontes, 2008.

ZANOTELLO, M.; ALMEIDA, M. J. P. M. de. Leitura de um texto de divulgação científica em uma disciplina de física básica na educação superior. Revista Ensaio - Pesquisa em Educação e Ciências, Belo Horizonte, v. 15, n. 3, p.113-130, setdez. 2013. Disponível em: <http://www.scielo.br/pdf/epec/v15n3/1983-2117epec-15-03-00113.pdf>. Acesso em: 16 ago. 2016.

Recebido: 30 nov. 2017

Aprovado: 08 fev. 2018

DOI: $10.3895 /$ actio.v3n2.7446

Como citar:

SETLIK, J.; HIGA, I. Percepções de estudantes de um curso de Licenciatura em Física sobre a leitura e a escrita no ensino e na aprendizagem de física. ACTIO, Curitiba, v. 3, n. 2, p. 18-38, mai./ago. 2018.

Disponível em: <https://periodicos.utfpr.edu.br/actio>. Acesso em: XXX

Correspondência:

Ivanilda Higa

UFPR, Setor de Educação, Departamento de Teoria e Prática de Ensino. Edifício D. Pedro I. Rua General Carneiro, 460. CEP 80060-150 - Curitiba, Paraná, Brasil.

Direito autoral: Este artigo está licenciado sob os termos da Licença Creative Commons-Atribuição 4.0

Internacional.

(c) (1) 